\title{
WAG Injection at Reservoir Conditions in a Layered Long - Core Loaded with a Live North Sea Crude
}

\author{
Akervoll I., Slotte P. A., Hansen A. G.
}

IKU, Norway

\begin{abstract}
Copyright 1995, Steering Committee of the European IOR - Symposium.
This paper was presented at the Bth. European IOR - Symposium in Vienna, Austria, May $16-17,1995$

This paper was selected for presentation by the Steering Committee, following roview of information contained in an abstract

submitted by the author(s). The paper, as presented has not been reviewed by the Steering Committee.
\end{abstract}

\begin{abstract}
Water-alternating-gas (WAG) and Combined water/gas (CWG) injection schemes have gained increasing interest in the recent years as a strategy to improve and accelerate oil recovery from North Sea Fields. Displacement experiments and long core experiments at reservoir conditions and simulation of the displacement behaviour, are steps in a procedure to qualify WAG injection through field pilots.
\end{abstract}

In the present paper, results from miscible WAG injection subsequent to waterflooding at reservoir conditions in a layered long core are presented. The layered core comprises a high permeability sandstone half-core mounted on top of (along length axis) a low permeability sandstone half-core with a casted layer of crushed and sieved sandstone in between. The casted layer provides communication between the two sandstones. The permeability of the casted layer was adjusted to be close to the low permeability layer. The capillary pressure relations from measured drainage processes of water-oil, water-gas, and oil-gas fluid pairs, the last at initial water saturation, were used.

The layered long core was loaded by recombined reservoir oil at initial water saturation, and equilibrated for three weeks. In the first water injection sequence, brine was injected until high water cut was established. Production volumes and flow parameters were continuously recorded. Subsequent to this, gas was injected until gas breakthrough had occurred and a high GOR was observed. Addi- tionally, three more WAG injection cycles were performed. The injection gas used was a hydrocarbon separator gas.

The experiment was simulated using a commercial compositional reservoir simulator. Simulations with and without molecular diffusion were performed. Capillary pressure curves used in the numerical simulations, have been measured on core plugs taken from the same block as the Bentheimer and Berea half-cores. The relative permeability curves were based on published data.

\section{INTRODUCTION}

Water-alternating-gas injection and Combined water/gas injection field pilots are currently being carried out at producing North Sea oil fields. Nonswept oil in layered and heterogeneous sandstone reservoirs, constitutes a high potential for improved oil recovery (IOR) by WAG and CWG injection schemes in waterflooded oil reservoirs.

A WAG process may also be designed to combine recovery of non-swept oil with recovery of capillary trapped oil after waterflooding and thereby add potential to the IOR target beyond that of improved sweep efficiency. In this sense, a miscible hydrocarbon WAG field pilot was initiated in 1994 at the Snorre Field in the North Sea. ${ }^{2}$

Displacement experiments carried out on long cores at reservoir conditions are of great value in the process of qualifying an IOR process for field 
candidates. Simulation of core-floods prior to the physical modelling in the laboratory gives valuable information when designing the displacement experiment in order to physically scale and model the targeted phenomena of interest. History matching core-floods by use of a reservoir simulator or a core-flood simulator is useful in analysing the flow pattern and understanding the displacement mechanism. Laboratory studies of gas and WAG injection with substantial amounts of net mass transfer between a volatile oil phase and injected separator gas at or close to multi-contact miscibility, and with use of compositional simulators to simulate and interpret the recovery mechanisms, have recently been reported by other research groups. ${ }^{3.45 .6}$

The purpose of the arrangement of the layered composite core, comprising two communicating sandstones with a permeability contrast and different capillary pressures, was to study the influence of capillary pressure and relative permeability on fluid flow communication between two sandstones. The crossflow of multi-contact miscible fluids between sandstone layers in communication are strongly affected by the viscous/gravity force ratio, ranging from flow regimes dominated by viscous fingering to regimes dominated by gravity override. A recent numerical study in homogeneous and heterogeneous porous media, with a span of mobility ratios relevant also for gas- and miscible WAG injection, reports on how 2-D and 3-D heterogeneous gridding affect the flow performance.'

The present paper presents petrophysics of the 60 $\mathrm{cm}$ long layered core, fluid properties, capillary pressure relations, and procedure for restoration of reservoir conditions in the layered core. The WAG injection sequences in the layered core and the results from WAG injection at reservoir conditions are also presented. The experiment was simulated using a commercial compositional reservoir simulator. Molecular diffusion was included in the simulations. The results from the high pressure WAG injection experiment is presented together with the results from the numerical simulations.

\section{EXPERIMENTAL MEASUREMENTS}

\section{The composite core}

The $60 \mathrm{~cm}$ long composite (split) core consists of one Bentheimer half-core comprising the top layer, one Berea half-core as the bottom layer, and a $2 \mathrm{~mm}$ thin layer made of crushed and sieved Berea in between, as shown in Figure 1. The half-cores were recovered from cores cleaved along the length axis and casted together to form a laminated, consolidated composite core. The permeability of the casted mid-layer could be adjusted by varying the grain size and combination of sieved sand batches, and thereby provide known communication between the two sandstones. ${ }^{8}$

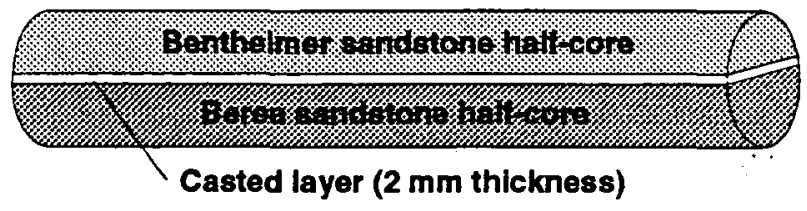

Figure 1. The layered long core.

Prior to cleaving the two cylindrical cores, the cores were cleaned and dried, and the Klinkenberg corrected air permeabilities and porosities were measured, as referred in Table 1. Cylindrical core samples of the mid-layer were casted for the purpose of porosity and permeability determination, and for testing of chemical tolerance and other properties.

Table 1. Key parameters of composite core.

\begin{tabular}{|l|c|c|}
\hline \multicolumn{1}{|c|}{ Layer of core } & $\begin{array}{c}\text { Permeability } \\
\text { (mD) }\end{array}$ & $\begin{array}{c}\text { Porosity } \\
\text { (fract.) }\end{array}$ \\
\hline Bentheimer & 2709 & 0.23 \\
Casted layer & 588 & 0.23 \\
Berea & 692 & 0.22 \\
Composite core & 1532 & 0.225 \\
\hline \multicolumn{2}{|l|}{ Composite core length: $59.9 \mathrm{~cm}$} \\
Composite core average diameter: $3.82 \mathrm{~cm}$ \\
Thickness of casted layer after hardening: $0.20 \mathrm{~cm}^{3}$ \\
Pore volume (PV) at ambient conditions: $155.8 \mathrm{~cm}^{3}$. \\
Calculated' PV at $90^{\circ} \mathrm{C}$ and 300 barg: $156.22 \mathrm{~cm}^{3}$ \\
(60 barg net confining sleeve pressure used in both \\
PV calculations).
\end{tabular}

The grain size combination that resulted in a permeability of the casted layer of $588 \mathrm{mD}$ was selected. The absolute permeability of the composite core while $100 \%$ saturated with lamp paraffin (60-100\% $\mathrm{C}_{9}-\mathrm{C}_{13}$ ) was determined to 1532 $\mathrm{mD}$.

The increase in pore volume by heating from room temperature to $90^{\circ} \mathrm{C}$ was corrected for the volumetric expansion of quartz, which is equal to $3.84 \times 10^{-5} \mathrm{~K}^{-1}$.

Series of surface permeability measurements were performed on the flat surfaces of the half-cores by use of a fully automated probe permeameter prior 
to coupling of the two pieces together. The measurements were successful, and the data obtained was used to calculate the permeability distribution in the reservoir simulation grids by a stochastic permeability generation algorithm. ${ }^{8}$

\section{Acquisition of initial water saturation}

The water drainage capillary pressure measurements in a high speed centrifuge gave initial water saturation $\left(S_{w i}\right)$ in Bentheimer and Berea sandstone of $12.6 \%$ and $19.7 \%$, respectively. The cores used in the capillary pressure measurements were taken from the same block of rock as the half-cores used in the composite core. In order to achieve $S_{w i}$ values in the layered composite core that were close to the values obtained from the $P_{c}$ measurements, volumes of brine that corresponded to the calculated $S_{w i}$ volumes in Bentheimer, Berea and Casted layer, were introduced to the surface of the respective layers of the composite core.

\section{Fluid preparation}

Separator liquid and gas samples from the Snorre Field in the North Sea were recombined in pre-calculated proportions in order to obtain a live reservoir crude with properties similar to live oil from a WAG pilot well subjected for fluid studies. The key properties of the recombined crude are given in Table 2. The GOR was determined during flooding the crude through the core and collecting stock tank oil in a thermostat water bath at $23^{\circ} \mathrm{C}$ and atmospheric pressure (defined as standard conditions for the separator both here and in the compositional simulations). All fluids were filtered $(0.45 \mu \mathrm{m})$ before entering the core holder.

Table 2. Properties of recombined crude.

\begin{tabular}{|l|c|l|}
\hline \multicolumn{1}{|c|}{ Property } & Value & \multicolumn{1}{c|}{ Conditions } \\
\hline Viscosity & $0.59 \mathrm{cP}$ & $90^{\circ} \mathrm{C}, 300 \mathrm{bar}$ \\
$B_{o}$ factor & $1.33 \mathrm{Rm} / \mathrm{Sm}^{3}$ & $90^{\circ} \mathrm{C}, 300 \mathrm{bar}$ \\
Density of STO & $835 \mathrm{~kg} / \mathrm{m}^{3}$ & $23^{\circ} \mathrm{C}, 1 \mathrm{~atm}$. \\
GOR & $103 \mathrm{Sm}^{3} / \mathrm{Sm}^{3}$ & \\
$P_{b}$, bubble point & $129.9 \mathrm{bar}$ & \\
\hline
\end{tabular}

Synthetic formation water was made after a prescription for the Snorre Field with physical properties as given in Table 3. This synthetic brine was used after degassing and filtering, both for obtaining $S_{w i}$ and in the WAG injection experiment.

The composition of the injection gas from GCanalysis is given in Table 4 . The viscosity of the injection gas at $90^{\circ} \mathrm{C}$ and 300 bar was calculated to $0.031 \mathrm{cP}$.

Table 3. Properties of synthetic formation water.

\begin{tabular}{|l|c|l|}
\hline Property & Value & \multicolumn{1}{|c|}{ Conditions } \\
\hline Viscosity & $0.342 \mathrm{cP}$ & $90^{\circ} \mathrm{C}, 300 \mathrm{bar}$ \\
Density & $1026.8 \mathrm{~kg} / \mathrm{m}^{3}$ & $20^{\circ} \mathrm{C}, 1 \mathrm{~atm}$. \\
$B_{w}$ & $1.02014^{\circ} \mathrm{Rm} / \mathrm{Sm}^{3}$ & $90^{\circ} \mathrm{C}, 300 \mathrm{bar}$ \\
Total sait & $37.8 \mathrm{~g} / 1$ & \\
$\mathrm{pH}$ & 7.66 & \\
\hline
\end{tabular}

"Calculated by use of data from Ref. 10 .

Table 4. Injection gas composition.

\begin{tabular}{|l|c|}
\hline Component & Concentration (mol\%) \\
\hline Nitrogen & 1.95 \\
Carbon dioxide & 0.416 \\
Methane & 70.39 \\
Ethane & 13.12 \\
Propane & 9.47 \\
n-butane & 2.34 \\
iso-butane & $1.08 \ldots$ \\
n-pentane & $0.608:$ \\
iso-pentane & 0.440 \\
n-hexane & 0.128 \\
n-heptane & 0.0589 \\
\hline
\end{tabular}

\section{Capillary pressure}

The capillary pressure measurements and results on Berea sandstone and fluid pairs were reported earlier. ${ }^{8}$ Similar measurements of capillary pressure on Bentheimer cores are reported by Hustad and Holt, and their results are included in the capillary pressure curves in Figure 2.

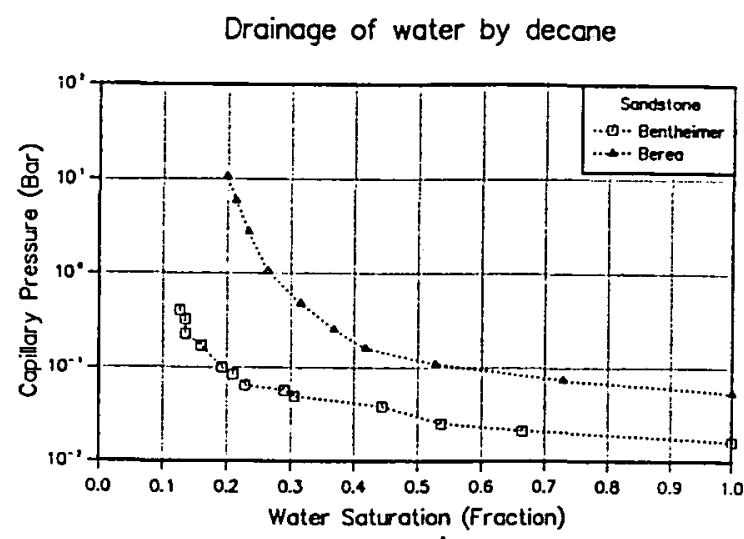

Figure $2 P_{c}$ vs. $S_{w}$ for drainage of decane by brine in Berea and Bentheimer. 
The figure shows the curves for drainage of brine by decane, measured in the centrifuge on Berea and Bentheimer core samples. The capillary pressure, including the entry pressure is, as expected, higher for Berea sandstone compared to Bentheimer sandstone.

\section{Core flood apparatus}

The displacement experiment was performed in a high pressure, high temperature flooding apparatus as shown in Figure 3 . The fluids produced at the outlet were recorded and collected for compositional analysis. The core holder was mounted horizontally next to the three high pressure fluid vessels, all inside the heating cabinet. The operating temperature of $90^{\circ} \mathrm{C}$ was maintained and the fluid vessels and core holder were connected to the pressure line of 300 bar. A data logger is an integrated part of the reservoir condition core flood apparatus.

\section{Restoration of reservoir conditions}

The composite core at $S_{w i}$ and air was mounted in the high pressure core-holder supplied with a soft gas diffusion stopper next to the core surface inside the witon sleeve. Then the air in the core was displaced by about 3 PV of water saturated propane gas, which was displaced with 2 PV watersaturated hexane, which finally was displaced with 3 PV light lamp paraffin. The $k_{o}$ at $S_{w i}$ was now measured to $1535 \mathrm{mD}$. The core was sealed at these conditions for 3 weeks. Then the temperature and pressure in the core was raised to $64^{\circ} \mathrm{C}$ and 35 barg, respectively (field separator conditions). The paraffin in the core was now substituted by injecting 2 PV separator liquid at a very low rate, in order to ensure replacement also in the low permeable layer. The core was equilibrated at $65^{\circ} \mathrm{C}$ and 98 barg for 3 weeks. The temperature and pressure was raised and the separator liquid in the core was displaced by injecting $2 \mathrm{PV}$ of recombined Snorre reservoir live crude at $90^{\circ} \mathrm{C}$ and 300 barg (reservoir conditions) at a very low rate, and further equilibrated in the core at these conditions for another week. Prior to the start of WAG injection, the $k_{o}$ at $S_{w i}$ was determined to be $1527 \mathrm{mD}$ by injecting live crude at reservoir conditions with a net confining sleeve pressure of 60 barg.

\section{WAG injection at reservoir conditions}

The elapsed time (hrs), injection fluid and cumulative injection volume $\left(\mathrm{Rcm}^{3}\right)$ are given in Table 5.

Table 5 shows real elapsed time from start of the WAG injection that included the following dead volumes; $0.5 \mathrm{Rcm}^{3} 100 \%$ filled with oil (at inlet side) and $1.35 \mathrm{Rcm}^{3} 100 \%$ filled with oil + $4.4 \mathrm{Rcm}^{3} 100 \%$ filled with water (both at outlet side) before the outlet production line enters the separator mounted in a water-bath at $23^{\circ} \mathrm{C}$ and atmospheric pressure.

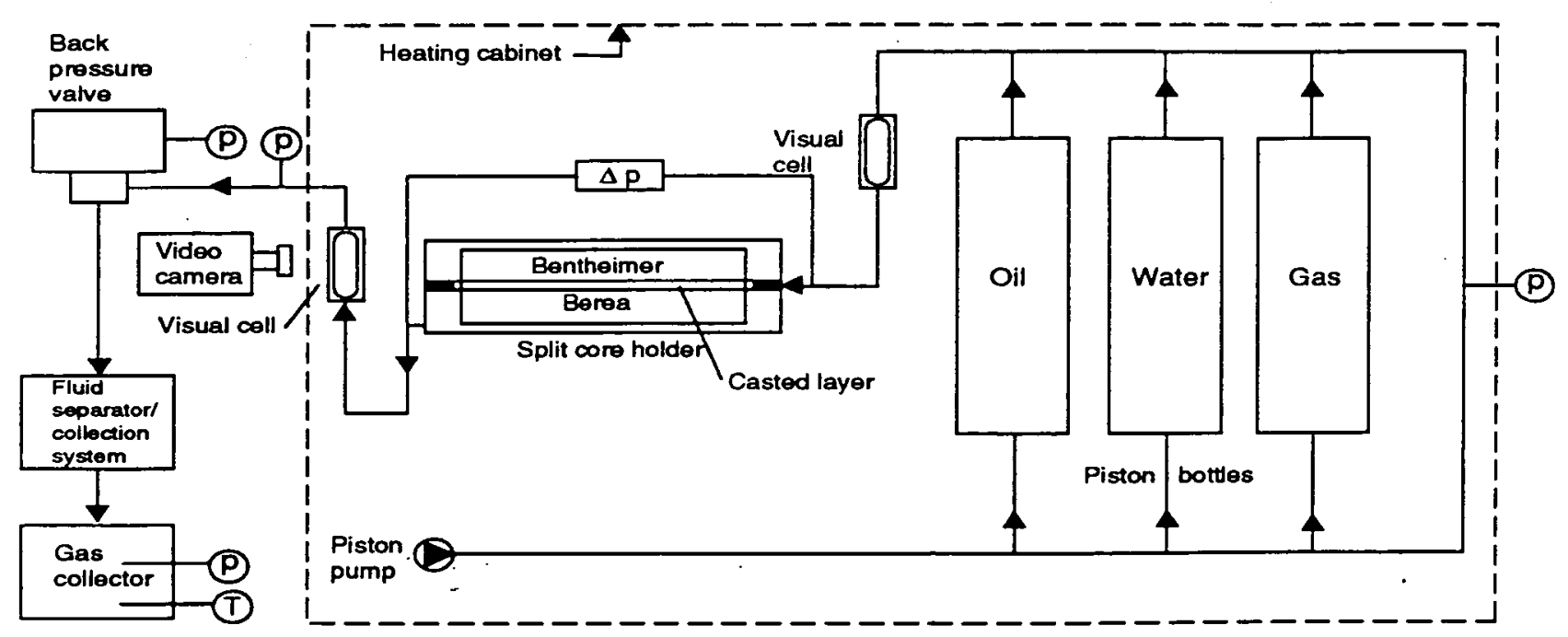

Figure 3 High pressure core flood apparatus. 
Table 5. Time and injection fluid volume.

\begin{tabular}{|c|c|c|c|}
\hline $\begin{array}{l}\text { Elapsed } \\
\text { time (hr) }\end{array}$ & $\begin{array}{l}\text { Injection fluid } \\
\text { and sequence }\end{array}$ & \begin{tabular}{|l|} 
Injection \\
vol. $($ Rcm 3$)$ \\
\end{tabular} & $\begin{array}{l}\text { Breakthrough times } \\
\text { of injection fluid }\end{array}$ \\
\hline 0.000 & Water seq.\#1 & 0.000 & \\
\hline 0.400 & Water seq.\#1 & 2.775 & \\
\hline 2.000 & Water seq.\#1 & 15.029 & \\
\hline 3.250 & Water seq.\#1 & 24.414 & \\
\hline 4.000 & |Water seq.\#1 & 30.151 & \\
\hline 4.583 & Water seq.\#1 & 34.838 & \\
\hline 6.000 & Water seq.\#1 & 45.518 & \\
\hline 8.000 & Water seq.\#1 & 60.908 & \\
\hline 9.583 & Water seq.\#1 & 73.337 & \\
\hline 10.000 & Water seq.\#1 & 76.391 & \\
\hline 10.500 & Water seq.\#1 & 80.309 & \\
\hline 10.850 & Water seq.\#1 & 82.874 & \\
\hline 11.267 & Water seq.\#1 & 86.115 & Water BT \\
\hline 11.450 & Water seq.\#1 & 88.937 & \\
\hline 11.883 & Water seq.\#1 & 90.989 & \\
\hline 12.000 & Gas seq.\#1 & 90.989 & \\
\hline 12.033 & Gas seq.\#1 & 117.684 & \\
\hline 12.250 & Gas seq.\#1 & 117.727 & \\
\hline 12.450 & Gas seq.\#1 & 119.367 & \\
\hline 12.583 & Gas seq.\#1 & 120.356 & \\
\hline 12.833 & Gas seq.\#1 & 122.223 & Gas BT \\
\hline 13.000 & Water seq.\#2 & 123.542 & \\
\hline 13.500 & Water seq.\#2 & 128.229 & \\
\hline 14.200 & Gas seq.\#2 & 133.805 & Water BT \\
\hline 15.383 & Gas seq.\#2 & 143.190 & \\
\hline 15.500 & Water seq.\#3 & 143.997 & Gas BT \\
\hline 15.917 & Water seq.\#3 & 147.448 & \\
\hline 16.750 & Water seq.\#3 & 153.908 & \\
\hline 16.917 & Water seq.\#3 & 155.167 & Water BT \\
\hline 17.000 & Gas seq.\#3 & 155.796 & \\
\hline 17.500 & Gas seq.\#3 & 159.760 & \\
\hline 18.500 & Gas seq.\#3 & 167.526 & \\
\hline 18.750 & All wells shut & 171.977 & Gas BT, Diffusion \\
\hline 40.517 & Water seq. \#4 & 171.977 & during 21.77 hrs. \\
\hline 40.850 & Water seq. \#4 & 183.217 & \\
\hline 41.017 & Gas seq.\#4 & 190.492 & \\
\hline 41.367 & Gas seq. & 205.377 & \\
\hline 41.667 & Gas seq.\#4 & 217.705 & \\
\hline 42.567 & Gas seg.\#4 & 253.503 & \\
\hline
\end{tabular}

In the first water injection sequence, brine was injected until high water cut was established. Production volumes and flow parameters were continuously recorded. Subsequent to this, gas was injected until gas breakthrough (BT), and a high GOR was observed. Then two more WAG injection cycles were performed, followed by a shut-in period. The experiment was concluded with a high rate WAG cycle.

\section{SIMULATION APPROACH}

The displacement experiment was simuliatêt using the commercial compositional simulator ECLIPSE $300 .^{12}$ This simulator has an option for including hysteresis in the relative permeability of the non wetting phases (gas and oil), but no hysteresis option for capillary pressures and wetting phase (water) relative permeability. Curves relevant for imbibition were used for $k_{\mathrm{rw}}$, and $P_{\text {cow }}$, while drainage curves were used for $P_{\text {cgo }}$. The ECLIPSE default model was used for three phase oil relative permeability.

Measured decane-water capillary pressures at ambient conditions (interfacial tension, $\sigma_{\mathrm{r}}=37.1 \mathrm{mN} / \mathrm{m}$ ), were transformed using the equation

$$
P_{\mathrm{c}}=\frac{\sigma}{\sigma_{\mathrm{r}}} P_{\mathrm{c}}^{\mathrm{r}},
$$

where the interfacial tension relevant for oil-brine at reservoir conditions is $\sigma=21.7 \mathrm{mN} / \mathrm{m}$. Since the process is miscible, oil-gas capillary presssures were set to zero.

The experiment was modelled by applying the following constraints:

- Experimental injection rate at the injection side.

- Fixed (bottom hole) pressure at the production side

The production was then compared with the measured data.

\section{Simulation grid}

To be able to accurately represent the flow pattern in the composite core, the permeability distribution of the simulation grid should reflect both the systematic and statistical variations of the true core. This is especially important in miscible displacement situations where permeability variations trigger viscous fingering. Surface permeability was measured with a mini-permeameter on the cleaved faces of the two half cores. The data from these measurements were incorporated into simulation grids using a simple stochastic permeability generation algorithm as described in Ref. 8. Stochastically generated permeabilities were used for Bentheimer and Berea, while the permeability of the casted layer was constant. Porosities were constant within each rock type. 
The experiment was simulated using a 3 dimensional Cartesian grid, where the transmissibilities, pore volumes, and block depths are corrected for the cylindrical shape of the core. The $(\mathrm{x}, \mathrm{y}, \mathrm{z})$-dimensions of the grid are $(28,3,12)$. The core is divided into 25 grid blocks of equal size in the x-direction, with dummy blocks at the end to represent end effects. The volumes of the dummies were chosen to equal the experimental dead volumes.

\section{Fluid characterisation}

The Soave Redlich Kwong cubic equation of state with a volume shift parameter was employed in the simulations. Eight pseudo components were used, and the equation of state (EOS) based package $\mathrm{PVT}^{13}$ was applied to tune the EOS to match experimental data. Results from pVT studies of fluids from two wells in the Snorre WAG pilot area were used in the tuning process. In addition, a match was made of measured gas-oil ratios and saturation pressures for four different compositions in the pressure-compositional space, in order to cover changes in oil composition during gas injection. After obtaining a match of the various measured data, the composition of the recombined reservoir oil used in the displacement experiment was determined by matching measured GOR, liquid density, viscosity, saturation pressure, and multi-contact miscibility pressure (MCMP). A MCMP of 292.6 bar was obtained.

The EOS parameters and fluid compositions used in the simulation are shown in Table 6 . All binary interaction parameters were set to zero.

The simulations were run with molecular diffusion included. The applied diffusivities are shown in Table 7.

Table $6 \quad$ Fluid compositions and EOS parameters for 8 pseudo components.

\begin{tabular}{|l|c|c|c|c|c|c|c|c|}
\hline $\begin{array}{c}\text { Comp. } \\
\text { name }\end{array}$ & $\begin{array}{c}\text { Oil } \\
\text { comp. } \\
\text { (mol \%) }\end{array}$ & $\begin{array}{c}\text { Inj. gas } \\
\text { comp. } \\
(\mathrm{mol} \%)\end{array}$ & $\begin{array}{c}\text { Mole } \\
\text { weight } \\
(\mathrm{g} / \mathrm{mol})\end{array}$ & $\begin{array}{c}\text { Critical } \\
\text { pressure } \\
\text { (bara) }\end{array}$ & $\begin{array}{c}\text { Critical } \\
\text { temp. } \\
(\mathrm{K})\end{array}$ & $\begin{array}{c}\text { Crit. vol. } \\
\left(\frac{\mathrm{m}^{3}}{\mathrm{~kg} \cdot \mathrm{mol}}\right)\end{array}$ & $\begin{array}{c}\text { Acentric } \\
\text { factor }\end{array}$ & $\begin{array}{c}\text { Volume } \\
\text { shift }\end{array}$ \\
\hline $\mathrm{HC1}$ & 26.068 & 72.756 & 17.44 & 43.11 & 186.90 & 0.1363 & 0.0145 & 0.0246 \\
$\mathrm{HC} 2$ & 10.103 & 13.120 & 30.07 & 51.04 & 268.53 & 0.1477 & 0.0980 & 0.0682 \\
$\mathrm{HC3}$ & 16.142 & 9.470 & 50.97 & 36.60 & 448.44 & 0.3122 & 0.1706 & 0.1031 \\
$\mathrm{HC5}$ & 10.451 & 4.468 & 78.38 & 27.05 & 722.19 & 0.6231 & 0.2657 & 0.1534 \\
$\mathrm{HC8}$ & 20.293 & 0.186 & 114.49 & 28.28 & 552.42 & 0.5480 & 0.5207 & 0.0095 \\
$\mathrm{HC15}$ & 6.906 & & 211.51 & 18.14 & 664.78 & 0.9138 & 0.7792 & 0.0166 \\
$\mathrm{HC} 24$ & 5.783 & & 338.71 & 15.10 & 771.81 & 1.1918 & 1.0587 & 0.0054 \\
$\mathrm{HC} 41$ & 4.254 & & 599.59 & 14.15 & 942.52 & 1.4607 & 1.2892 & -0.0216 \\
\hline
\end{tabular}

Table 7 Diffusivities.

\begin{tabular}{|l|c|c|}
\hline $\begin{array}{l}\text { Component } \\
\text { name }\end{array}$ & $\begin{array}{c}\text { Oil diffusivity } \\
10^{-5} \mathrm{~cm}^{2} / \mathrm{s}\end{array}$ & $\begin{array}{l}\text { Gas } \\
\text { diffusivity } \\
10^{-5} \mathrm{~cm}^{2} / \mathrm{s}\end{array}$ \\
\hline HC1 & 1.0 & 10.0 \\
\hline HC2 & 0.5 & 5.0 \\
\hline HC3 & 0.25 & 2.5 \\
\hline HC5 & 0.0 & 0.278 \\
\hline HC8 & 0.0 & 0.0 \\
\hline HC15 & 0.0 & 0.0 \\
\hline HC24 & 0.0 & 0.0 \\
\hline HC41 & 0.0 & 0.0 \\
\hline
\end{tabular}




\section{RESULTS AND DISCUSSIONS}

The main results of the displacement experiment and simulation are shown in Figures 4 and 5.
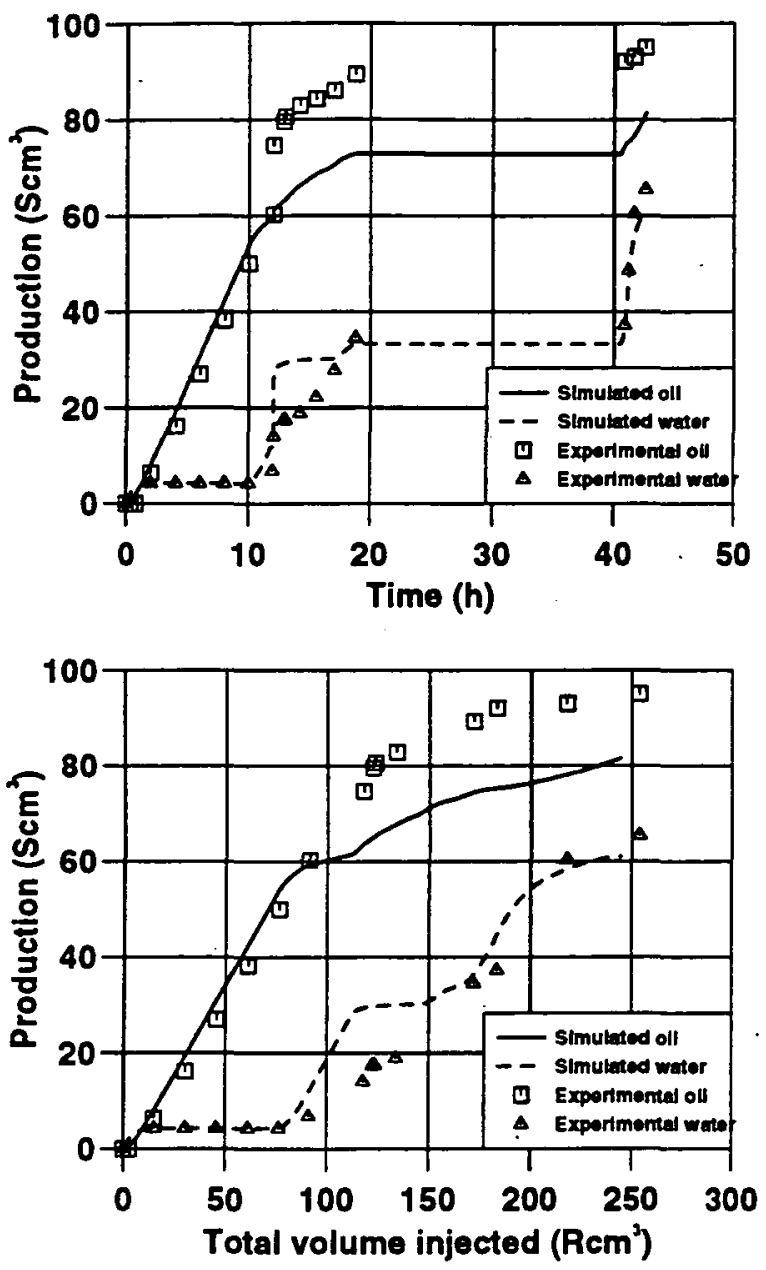

Figure 4 Simulated and experimental total oil and water production vs. time (top), and total injected reservoir volume (bottom).

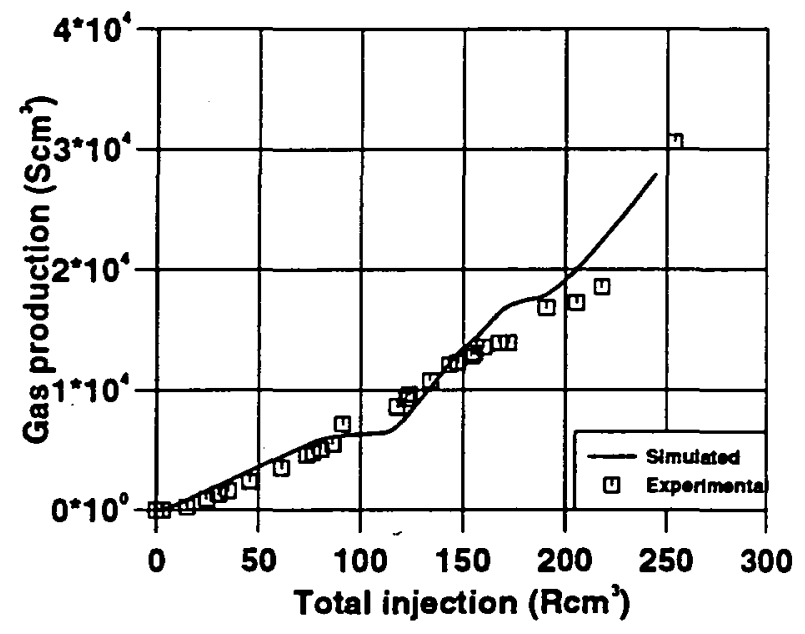

Figure 5 Simulated and experimental gas production.
In the presented simulation results, relative permeabilities for Berea was taken from Oak, ${ }^{14}$ the data from Hustad and Hólt was used for Bentheimer, and the casted layer relative permeability was based on Berea data, with a shift in the end points reflecting a higher critical water saturation $S_{w c}=0.45$ as indicated by Computer Tomography measurements.

The main difference between the simulated and experimental results, stems from an earlier water breakthrough in the simulation. A history match based on a reduced $k_{\mathrm{rw}}$, and/or reduced irreducible oil saturations, $S_{\text {orw }}$, would give the correct breakthrough time.

The abrupt increase in the experimental oil recovery curve at the start of the first gas injection sequence, is due to the very high injection rate during the first two minutes of this injection sequence. The gas injection rate during this period was calculated based on the oil and brine produced into the separator at standard conditions. The amount of gas that dissolved into the oil phase during this period, was not included in the gas injection rate used in the numerical simulator. An increase in the gas injection rate in the simulation might give a better match of the experimental curve.

It seems, however, that the qualitative aspects of the displacement processes are well captured by applying the independently measured relative permeability data.

Insight into the displacement mechanisms may be gained by studying simulated saturation profiles.

Figure 6 shows the water saturation during the initial water flood. The displacement process takes place under vertical capillary equilibrium, and the water breaks through when an almost constant (critical) saturation is reached in each rock type.

Figure 7 illustrates the displacement process during the first gas cycle. The gas segregates rapidly to the top. In this miscible process the actual sweep is, however, much more efficient than the gas sweep indicates. The composition of the reservoir oil changes, with a dramatic increase in the methane concentration over a wider area.

During the 21.77 hours shut-in period, the light components diffuse slowly downwards into the Berea zone. This process leads to a reduced gas volume, and, in the simulation, the pressure is reduced from $296 \mathrm{bar}$ to $283 \mathrm{bar}$. The diffusion process is slower than what might be expected 
from simple diffusion calculations. This is due to the fact that both gravity and the reduced gas volume counteract the downwards diffusive flux. The effect of diffusion is illustrated in Figure 8.

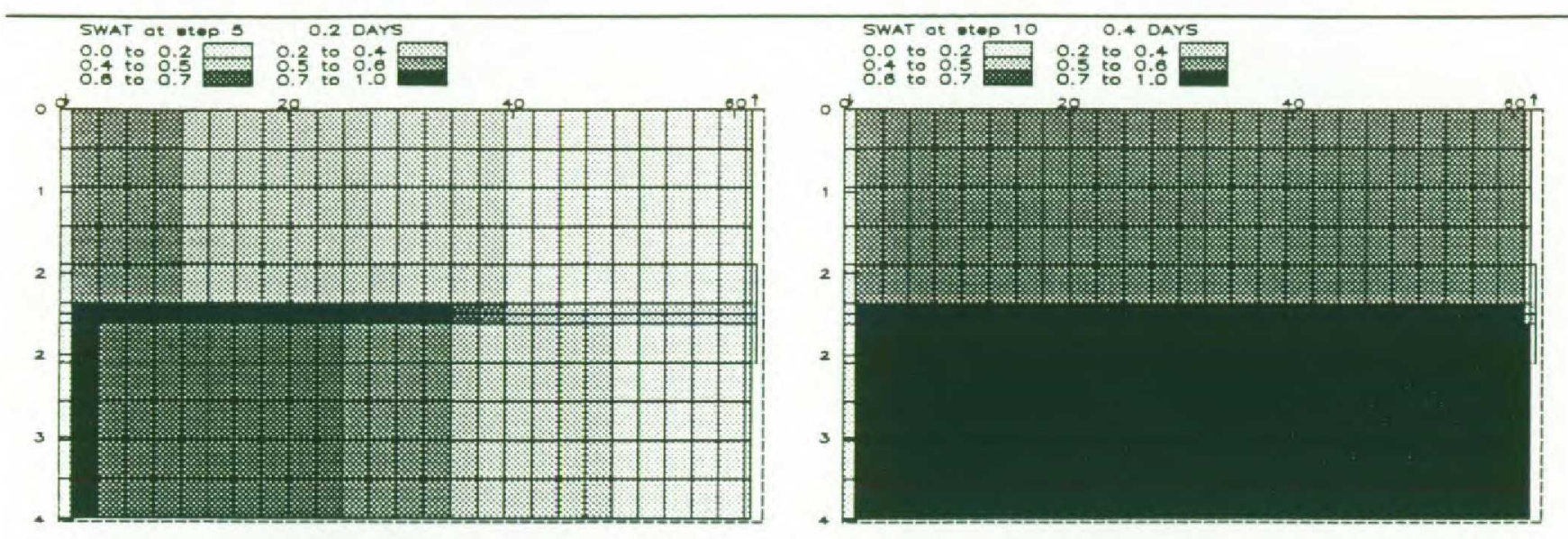

Figure 6 Water saturation during initial (reservoir rate) waterflood. After $5 \mathrm{~h}$ (left), and after $10 \mathrm{~h}$, just after water breakthrough, (right).
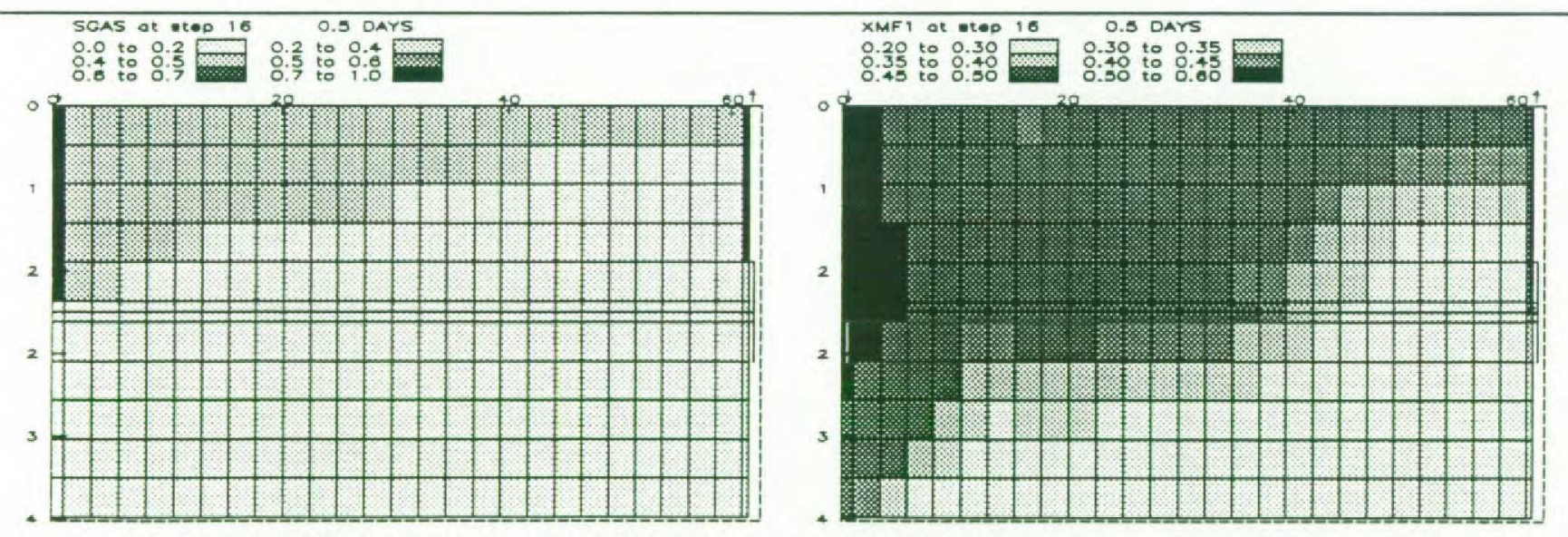

Figure 7 Gas saturation (left), and mole fraction of the lightest hydrocarbon component in the oil phase (right), during the first gas injection cycle $(12.5 \mathrm{~h})$. 


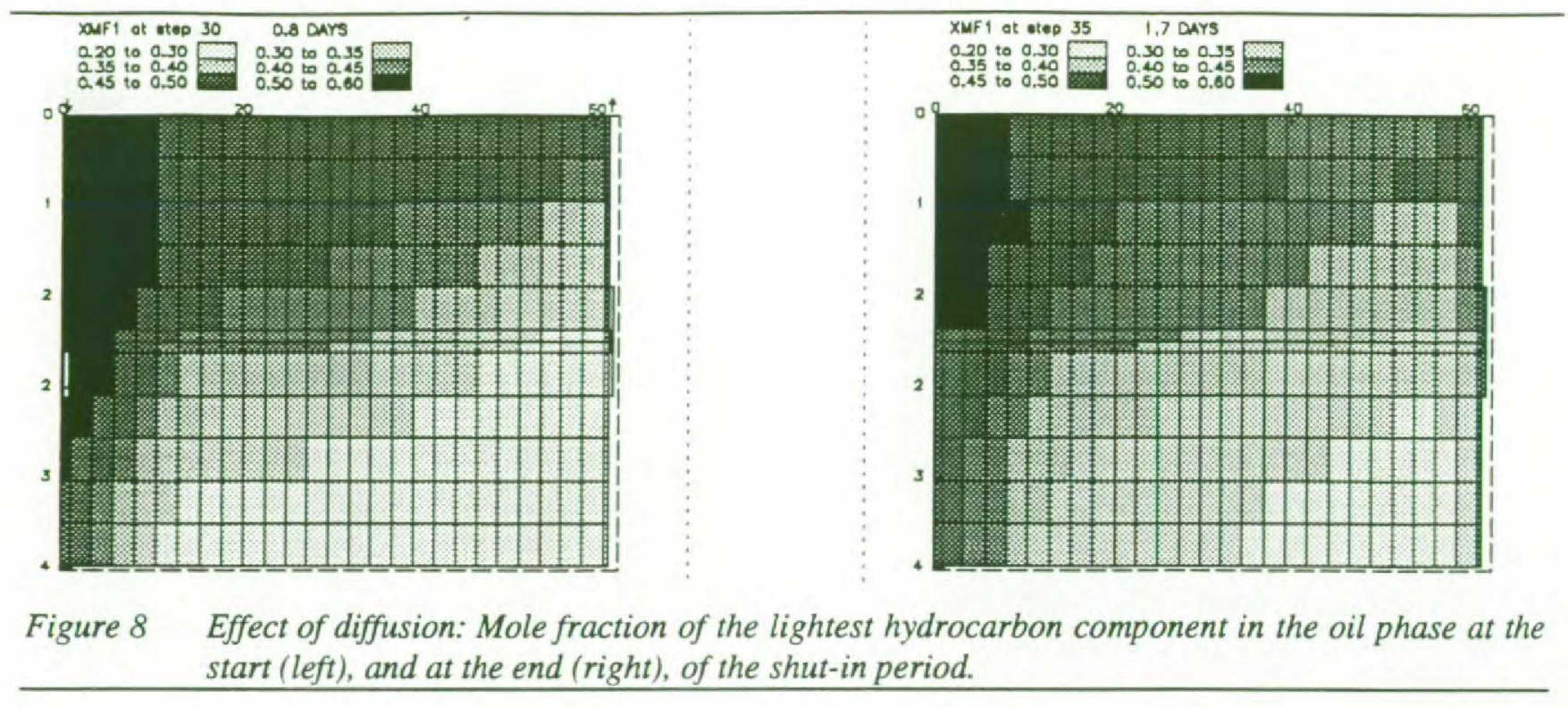

Figure 9 shows the final sweep in terms of the light component mole fraction in oil.

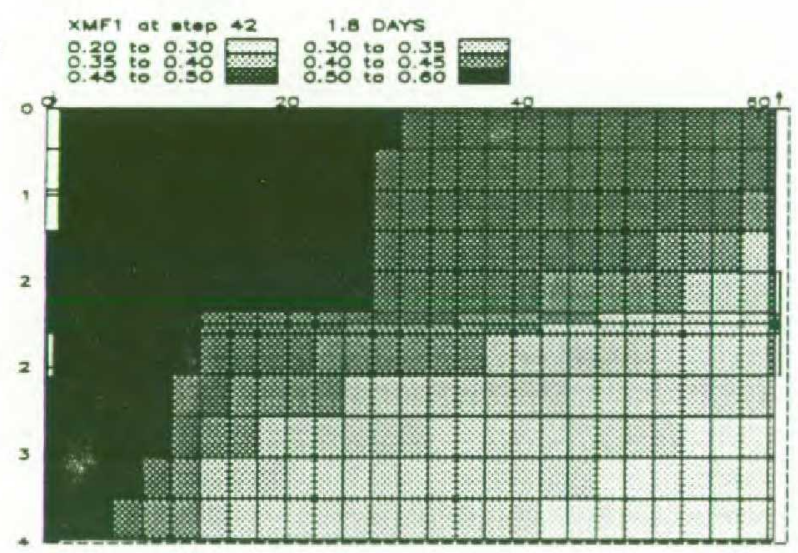

Figure 9 Mole fraction of the lightest hydrocarbon component in the oil phase at the end of gas cycle \#4.

\section{CONCLUSIONS}

The capillary forces dominated the behaviour of the waterflood at low front velocity $(v=1 \mathrm{~m} /$ day $)$ in the layered core.

The viscous forces dominated the flow behaviour at higher front velocity (above $10 \mathrm{~m} /$ day).

WAG injection in the layered core raised the experimental recovery factor from $59 \%$ after waterflood to $95 \%$ at the end of the experiment.

The effect of diffusion is smaller than what might be expected from diffusivity calculations. This is due to reduced gas volume and gravitational seg- regation, both induced by the diffusion, that counteract the diffusional flux.

\section{NOMENCLATURE}

A Cross section area of the core

$B_{o} \quad$ Oil formation volume factor

$B_{w} \quad$ Water formation volume factor

GOR Gas oil ratio

$k \quad$ Absolute permeability

$k_{o} \quad$ Oil permeability

$k_{n w} \quad$ Water relative permeability

p Pressure

$p_{b} \quad$ Bubble point pressure

$P_{c} \quad$ Capillary pressure

$P_{c g o} \quad$ Gas-oil capillary pressure

$P_{\text {cow }}$ Oil-water capillary pressure

$P_{c}^{r} \quad$ Reference capillary pressure

PV Pore volume

Q Volumetric injection rate

$\mathrm{Rcm}^{3}$ Reservoir $\mathrm{cm}^{3}$

$\mathrm{Scm}^{3} \quad$ Standard $\mathrm{cm}^{3}$

$S_{\mathrm{o}} \quad$ Oil saturation

$S_{\text {onw }}$ Residual oil saturation to water

$S_{w} \quad$ Water saturation

$S_{w c} \quad$ Critical water saturation

$S_{w i} \quad$ Initial water saturation

$\mathrm{v} \quad=\mathrm{Q} /(\mathrm{A} \cdot \phi)$, front velocity.

$\mu \quad$ Viscosity

$\phi \quad$ Porosity

$\sigma_{r} \quad$ Reference interfacial tension

$\sigma \quad$ Interfacial tension 


\section{REFERENCES}

1. IOR Strategy Workshop arranged 21-22 Feb. 1995. Bergen, Norway by IKU Petroleum Research, Rogaland Research and PETEC.

2. Diesen, G. W., Øritsland, S. and Grevstad, P.: "Snorre Field Reservoir and Development Plans - Importance of Reservoir Management and Early Field Performance, presented at The 5th Conference on Reservoir Management, 11-12 Oct. 1994, Stavanger Forum, Stavanger.

3. Szabo, D.J. and Meyers, K.O.: "Prudhoe Bay Development History and Future Potential", 7th European IOR Symposium, Moscow, Oct. 27-29, 1994, proc., Vol 2, 528-541.

4. McGuire, P. L., Spence, A. P., Stalkup, F. I. and Cooley, M. W.: "Core Acquisition and Analysis for Optimization of the Prudhoe Bay Miscible Gas Project", SPE/DOE 27759 paper at 9th Symposium on IOR, Tulsa, Ok, 17-20 April 1994, Vol 1, 253-266.

5. Espie, A. A., Brown, C. E., Merrill, R. C. and Newley, T.M.J.: "An Evaluation of Oil Recovery by Vaporisation", SPE/DOE 27759 paper at 9th Symposium on IOR, Tulsa, Ok, 17-20 April 1994, Vol 2, 321-332.

6. Madaoui, K. and Sakthikumar, S.: " Lean Gas Injection in Water Flooded Oil Reservoirs: A Systematic Investigation for Field Application", paper presented at the 7th European Symposium on IOR, Moscow, Oct. 27-29, 1993, proc., Vol. 1, 445-459.

7. Tchelepi, H. A. and Orr, F. M. Jr.: "Interaction of Viscous Fingering, Permeability Heterogeneity, and Gravity Segregation in Three Dimensions", SPERE (Nov. 1994) 266.

8. Akervoll, I., Borud, K. and Slotte, P. A.: "Displacements in Two-Layered, Consolidated Flow Model - Physical and Numerical Modelling", paper \#12 at IEA Collaborative Project on Enhanced Oil Recovery - 15th International Workshop and Symposium, Bergen Norway, 28-31 August, 1994.

9. Perry, R.H., Green, D.: Perry's chemical engineer's handbook, McGraw-Hill Book Co., New York 1984.

10. Engineering Science Data, Item No. 68010, Density of Water Substance, Table III, June 1968.
11. Hustad, O.S. and Holt, T.: "Gravity Stable Displacement of Oil by Hydrocarbon Gas After Water Flooding", paper SPE/DOE 24116 presented at the 1992 Symposium on Enhanced Oil Recovery, Tulsa (April 22-24).

12. ECLIPSE 300 Technical Description, 94a version, Intera Information Technologies, 1994.

13. PVT Reference Manual, 94 a version, Intera Information Technologies, 1994.

14. Oak, M. J.: "Three-Phase Relative Permeability of Water-Wet Sandstone," F89-P-7 4 (210-10-13), 89312 ART0196 (Nov. 8, 1989).

\section{ACKNOWLEDGEMENT}

The RUTH Combined Gas/Water Injection Subprogram was initiated by the Norwegian Authorities and is financially supported by the Research Council of Norway. Additional to this, the program is supported by technical assistance, quality control and finance through 4 years by the following oil companies;

Amoco Norway, Conoco Norway, Elf Petroleum Norway, Enterprise Oil, Idemitsu, Neste Petroleum, Norsk Agip, Norsk Hydro, Phillips Petroleum Norway, Saga Petroleum, Svenska Petroleum and Total Norge.

The grants as well as the technical support are gratefully acknowledged. 